\title{
miRNA-766 induces apoptosis of human colon cancer cells through the p53/Bax signaling pathway by MDM4
}

\author{
WEIRONG CHEN, GAOYANG CAI, ZIQUN LIAO, KAIHUANG LIN, GUANGRONG LI and YANCHONG LI \\ Department of General Surgery, Second Affiliated Hospital, Shantou University Medical College, \\ Shantou, Guangdong 515041, P.R. China
}

Received May 18, 2018; Accepted February 18, 2019

DOI: $10.3892 /$ etm.2019.7436

\begin{abstract}
RNAs are closely associated with tumor genesis and development. The present study investigated the role of the expression of miRNA-766 in the survival of patients with colon cancer and the underlying molecular mechanisms. Reverse transcription-quantitative polymerase chain reaction analysis and microarray analysis were used to analyze the expression of miRNA-766. The results revealed that the expression of miRNA-766 was decreased in patients with colon cancer. The overall survival and disease-free survival rates of patients with colon cancer with a high expression of miRNA-766 were prolonged, compared with those with a low expression of miRNA-766. The overexpression of miRNA-766 reduced cell growth and induced apoptosis in colon cancer cells through suppression of the MDM4/p53 pathway. By contrast, the downregulation of miRNA-766 promoted cell growth and reduced apoptosis in colon cancer cells through activation of the MDM4/p53 pathway. The promotion of MDM4 attenuated the anticancer effect of miRNA-766 in colon cancer cells. These results demonstrated that miRNA-766 induced cell apoptosis in human colon cancer through MDM4/p53.
\end{abstract}

\section{Introduction}

Colon cancer is one of the most common malignancies severely threatening human health (1). It ranks third highest worldwide in terms of cancer-associated mortality rates (1). According to statistics, there were $\sim 1,000,000$ new cases of colon cancer in 2008 worldwide, and $\sim 500,000$ individuals succumbed to mortality (2). The morbidity rate of colon cancer in China has exhibited an increasing trend in recent years. This can

Correspondence to: Dr Weirong Chen, Department of General Surgery, Second Affiliated Hospital, Shantou University Medical College, 69 Dongxia North Road, Shantou, Guangdong 515041, P.R. China

E-mail: chenwe407@yeah.net

Key words: microRNA-766, MDM4, human colon cancer, B-cell lymphoma 2-associated $\mathrm{X}$ protein, $\mathrm{p} 53$ be ascribed to improvements in nationwide living standards, changes in dietary patterns, aging of the population, and rapid developments in endoscopy $(3,4)$. Therefore, colon cancer has become a serious threat to human health aslone of the most common malignancies $(3,4)$.

Colon cancer has a high mortality rate regardless of the advances in surgical technology and other treatments and despite novel molecular preparations emerging in previous years (5). This may be attributed mainly to the frequent recurrence and metastasis of colon cancer (5). Therefore, early diagnosis and treatment is of significance for improving prognosis of patients with colon cancer (5). At present, the mechanism underlying its tumorigenesis remains to be fully elucidated. Understanding its corresponding mechanism is important to develop novel strategies and identify novel target genes for effectively treating colon cancer (6).

MicroRNAs are types of small non-coding RNA molecule of $\sim 19-24$ nucleotides in length (7). They are relatively conserved during biological evolution and do not encode protein. However, they can regulate target genes through directly binding with the 3'untranslated region (3'-UTR) of target mRNA (8).

It has been demonstrated in previous years that miRNAs are closely associated with tumor genesis and development. Compared with normal tissue, the miRNA expression profile in tumor tissue is significantly altered. Furthermore, miRNAs interact with traditional tumor suppressor genes and oncogenes (9). Therefore, they have dual-identity during tumorigenesis and development. It is estimated that $>50 \%$ of miRNA upstream regulatory genes locate in tumor-associated regions in chromosomes. There are a variety of miRNAs, including those functioning as oncogenes and others as tumor suppressor genes. miRNAs can exert oncogenic functions, inhibit the expression of tumor suppressor genes, and provide favorable conditions for tumor proliferation, migration, metastasis and infiltration (10). By contrast, they can function as a tumor suppressor gene, inhibit expression of oncogene, and contribute to tumor cell apoptosis, differentiation and treatment (11). The earliest report regarding the correlation between miRNA and tumors was of the 13q14 gene deletion in chronic lymphocytic leukemia (11). The oncogene miRNA17-92' was the first miRNA identified in mammals (11); it shows abnormally increased expression in lung cancer and lymphoma. Mutation in relevant miRNAs 
can activate the expression of its oncogene or induce loss or changes in a tumor suppressor gene, which results in tumor genesis and development (11).

MDM4 is a type of proto-oncogene locating in chromosome 1q23, which encodes 11 exons and 490 amino acids (8). The MDM4 protein structure includes a p53-binding domain (p53 BD) locating in the N-terminal, and an amino acid region locating in the RING figure domain and center (8). The RING finger domain is the major determinant of MDM4 and MDM2 acting on p53 (8), and a heterodimer can be formed through the domain (8). MDM4 binds with p53 through p53BD in its $\mathrm{N}$-terminal, and inhibits the transcriptional activity of p53. It has been verified in a previous study that MDM4 is partly correlated with tumors (12). For example, the overexpression of MDM4 can be detected in certain human tumor cell lines, and MDM4 proliferation has be found in solid tumors, including breast cancer and colon cancer $(7,12)$. Therefore, it is hypothesized that MDM4 in human tumors can promote tumor genesis or progression. The present study investigated whether the role of the expression of miRNA-766 affects human colon cancer survival rate and examined the underlying molecular mechanisms.

\section{Materials and methods}

Study population. A total of 102 patients with human colon cancer and 57 normal volunteers were recruited from the Second Affiliated Hospital, Shantou University Medical College (Shantou, China) from March 2012 to July 2012. Colon cancer tissue samples were acquired in patients undergoing surgery, and para-carcinoma tissues were collected at a distance of $5 \mathrm{~cm}$ from the cancer tissue samples. The present study was approved by the Ethical Agent Will of the Second Affiliated Hospital, Shantou University Medical College.

Reverse transcription-quantitative polymerase chain reaction (RT-qPCR) analysis. Total RNA was isolated using a TRIzol-based (Invitrogen; Thermo Fisher Scientific, Inc., Waltham, MA, USA) RNA isolation protocol and $500 \mathrm{ng}$ RNA was reverse transcribed using the TaqMan microRNA Reverse Transcription kit (Applied Biosystems; Thermo Fisher Scientific, Inc.). RT-qPCR analysis was performed using SYBR-Green PCR Master Mix (PE Applied Biosystems; Thermo Fisher Scientific, Inc.) with the Applied Biosystems 7900HT real-time PCR machine (Applied Biosystems; Thermo Fisher Scientific, Inc.). The reaction conditions were as follows: Hot start at $94^{\circ} \mathrm{C}$ for $10 \mathrm{~min}$; 40 cycles of $30 \mathrm{sec}$ at $95^{\circ} \mathrm{C}, 30 \mathrm{sec}$ at $60^{\circ} \mathrm{C}$ and $30 \mathrm{sec}$ at $72^{\circ} \mathrm{C}$, and $10 \mathrm{~min}$ at $72^{\circ} \mathrm{C}$. miR-766 forward, $5^{\prime}$-TCGAGTA CTTGAGATGGAGTTTT-3' and reverse, 5'-GGCCGCGTT GCAGTGAGCCGAG-3'; U6 forward, 5'-GCTTCGGCA GCACATATACTAAAAT-3' and reverse, 5'-CGCTTCACG AATTTGCGTGTCAT-3'. miRNA expression was measured using $2^{-\Delta \Delta c q}(13)$.

Microarray analysis. RNA cleanup was performed using the RNeasy Mini kit (Qiagen, Inc., Valencia, CA, USA). Total RNA was reverse transcribed into cDNA using an oligo d(T) (Bio-Rad Laboratories, Inc., Hercules, CA, USA). cRNA was hybridized onto the Affymetrix Human
Table I. Distribution of selected characteristics among patients with colon cancer and controls.

\begin{tabular}{lccc}
\hline Characteristic & $\begin{array}{c}\text { Colon cancer, } \\
\mathrm{n}(\%)\end{array}$ & $\begin{array}{c}\text { Control, } \\
\mathrm{n}(\%)\end{array}$ & P-value \\
\hline $\begin{array}{l}\text { Number of individuals } \\
\text { Age (years) }\end{array}$ & 102 & 57 & \\
$<60$ & $57(55.88)$ & $31(54.39)$ & \\
$<60$ & $45(44.12)$ & $26(45.61)$ & \\
Sex & & & \\
Male & $78(76.47)$ & $46(80.70)$ & \\
Female & $24(23.53)$ & $11(19.30)$ & \\
Smoking status & & & 0.009 \\
No & $41(40.20)$ & $31(54.39)$ & \\
$\quad$ Yes & $61(59.80)$ & $26(45.61)$ & \\
Drinking status & & & $<0.001$ \\
No & $37(36.27)$ & $33(57.89)$ & \\
Yes & $65(63.73)$ & $24(42.11)$ & \\
\hline
\end{tabular}

Genome U133 Plus 2.0 Array, staining was performed with a Fluidic Station-450 and GeneChips were scanned with the Affymetrix GeneChip Scanner 7G. Data were quantified and feature-extracted using Agilent Feature Extraction software (version A.10.7.3.1; Agilent Technologies, Inc., Santa Clara, CA, USA).

Cell culture and cell transfection experiments. Human Caco2 cells were purchased from Type Culture Collection of the Chinese Academy of Sciences (Shanghai, China) and cultured in Dulbecco's minimal essential medium (DMEM; GE Healthcare Life Sciences, Logan, UT, USA), 10\% fetal bovine serum (FBS; GE Healthcare Life Sciences) at $37^{\circ} \mathrm{C}$ in 5\% CO2 and 95\% relative humidity. miRNA (miR)-766 mimics and negative control mimics were purchased from Sangon Biotech Co., Ltd. (Shanghai, China). Subsequently, $20 \mathrm{ng} / \mathrm{ml} \mathrm{miR}-766$, anti-miR-766 mimics and negative control mimics were transfected into $\mathrm{Caco} 2$ cells using Lipofectamine 3000 (Invitrogen; Thermo Fisher Scientific, Inc.) according to the manufacturer's protocol.

Cell viability assay and analysis of apoptosis. The cells $\left(1 \times 10^{6} \mathrm{cell} / \mathrm{ml}\right)$ were incubated with medium containing MTT (5 $\mathrm{mg} / \mathrm{ml}$ ) for $4 \mathrm{~h}$ and dissolved with $150 \mu \mathrm{l}$ DMSO. The medium was removed and dissolved with $150 \mu \mathrm{l}$ DMSO for $15 \mathrm{~min}$ at room temperature. The absorbance was measured at $490 \mathrm{~nm}$ using a microplate reader.

To analyze apoptosis, the cells were washed twice with ice-cold PBS and resuspended in $500 \mu \mathrm{l}$ binding buffer (Nanjing KeyGen Biotech Co., Ltd., Nanjing, China). Subsequently, $5 \mu \mathrm{l}$ annexin $\mathrm{V}$-fluorescein isothiocyanate and $5 \mu \mathrm{l}$ propidium iodide (both Nanjing KeyGen Biotech Co., Ltd.) were added and the cells were incubated for $15 \mathrm{~min}$ at room temperature in the dark. Apoptosis was analyzed using a FACSort flow cytometer and quantified using BD CellQuest ${ }^{\mathrm{TM}}$ Pro software (BD Biosciences, Franklin Lakes, NJ, USA). 
A
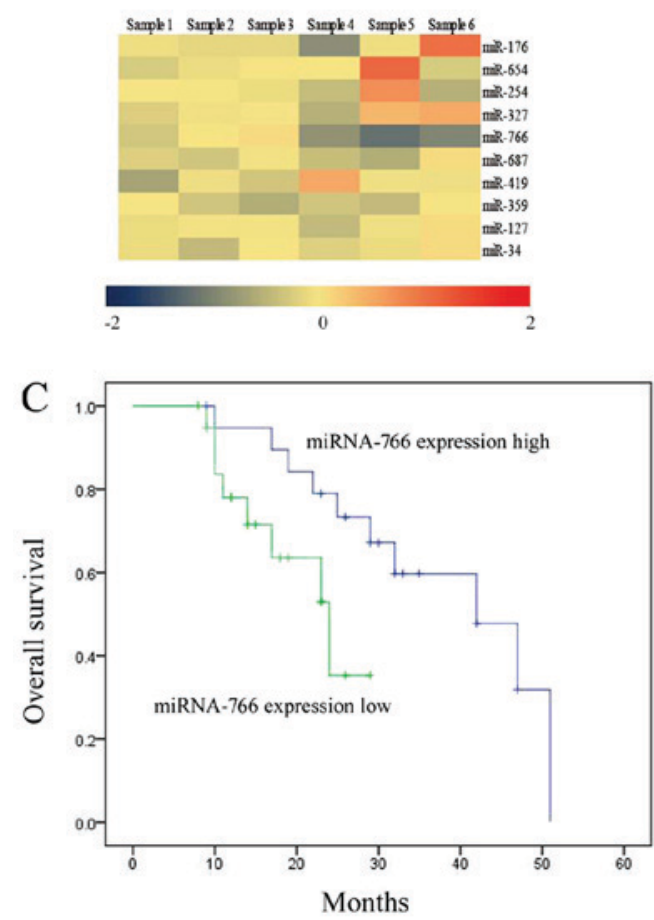

B

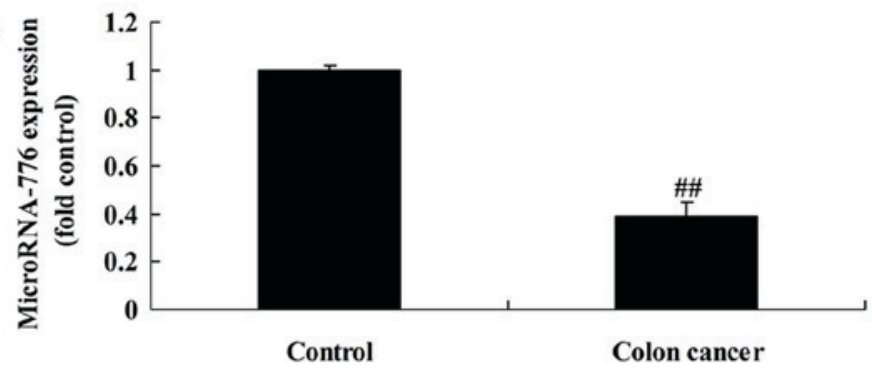

D

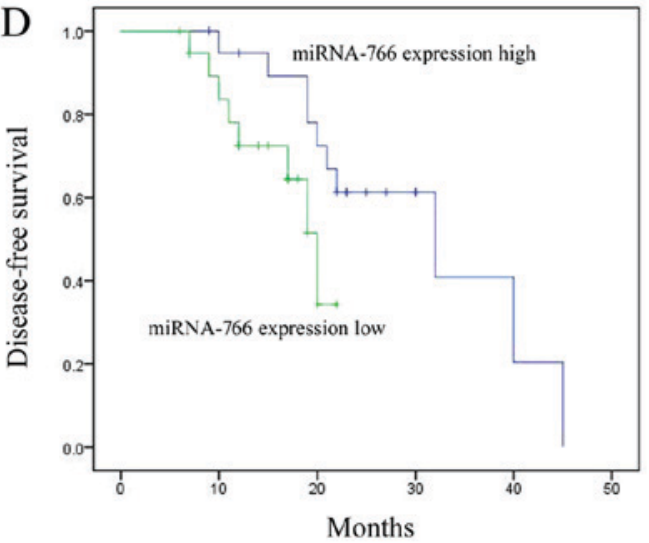

Figure 1. Expression of miR-766 in patients with colon cancer. (A) Heat map and (B) reverse transcription-quantitative polymerase chain reaction analyses of the expression of miR-766 in patients with colon cancer. (C) Overall and (D) disease-free survival rates of patients with colon cancer with differing expression levels of miR-766. ${ }^{\#} \mathrm{P}<0.01$ vs. Control. Control, 57 normal volunteers; Colon cancer, 102 patients with colon cancer; miR/miRNA, microRNA.

Cell migration assay. The Caco 2 cells $\left(1 \times 10^{5}\right.$ cell $\left./ \mathrm{ml}\right)$ were seeded on 24-well plates and were added to the upper chamber of each migration well (Corning Corporation, Corning, NY, USA). DMEM (500 $\mu \mathrm{l})$ with $20 \%$ FBS was added to the lower chamber and incubated for $48 \mathrm{~h}$ at $37^{\circ} \mathrm{C}$. The lower side were fixed with $75 \%$ ice-alcohol for $30 \mathrm{~min}$ and stained with $1 \%$ crystal violet solution for $1 \mathrm{~h}$ at room temperature. The cells were counted under a fluorescence microscope (Axio version II, Carl Zeiss AG, Oberkochen, Germany).

Western blot analysis. Total protein was extracted in RIPA buffer (Beyotime Institute of Biotechnology, Haimen, China) on ice for $30 \mathrm{~min}$ and then centrifuged at $12,000 \mathrm{x} \mathrm{g}$ for $10 \mathrm{~min}$ at $4^{\circ} \mathrm{C}$. Total protein was quantified using a BCA assay (Beyotime Institute of Biotechnology) and total protein samples $(50 \mu \mathrm{g})$ were subjected to 8-12\% SDS-polyacrylamide gel electrophoresis and then transferred onto PVDF membranes. The membranes were blocked with 5\% skimmed milk in TBST, and incubated at $4{ }^{\circ} \mathrm{C}$ overnight with the following primary antibodies: MDM4 (cat. no. sc-14738; 1:1,000; Santa Cruz Biotechnology, Inc., Dallas, TX, USA), B-cell lymphoma 2-associated X protein (Bax; cat. no. sc-6236, 1:1,000), p53 (cat. no. sc-47698; 1:1,000) and GAPDH (cat. no. sc-51631; 1:5,000; all Santa Cruz Biotechnology). The membranes were washed with TBST for $15 \mathrm{~min}$ and then incubated with the anti-rabbit horseradish peroxidase secondary antibody (cat. no. sc-2004; 1:5,000; Santa Cruz Biotechnology, Inc.) for $1 \mathrm{~h}$ at $37^{\circ} \mathrm{C}$. The protein bands were detected with enhanced chemiluminescence (Beyotime Institute of Biotechnology).
Analysis of capase-3/9 activity levels. Total protein was extracted using RIPA buffer (Beyotime Institute of Biotechnology) on ice for $30 \mathrm{~min}$ and then centrifuged at $12,000 \mathrm{x}$ g for $10 \mathrm{~min}$ at $4^{\circ} \mathrm{C}$. Total protein was quantified using a BCA assay (Beyotime Institute of Biotechnology) and total protein samples $(10 \mu \mathrm{g})$ were used to measure the capase-3/9 activity levels using capase-3/9 activity kits. The absorbance was measured at $405 \mathrm{~nm}$ using a microplate reader.

Statistical analysis. The data are expressed as the mean \pm standard deviation. All statistical analyses were performed using SPSS version 18.0 statistical software (SPSS, Inc., Chicago, IL, USA). Statistical comparisons of $>2$ or three groups were performed using Student's t-test or a one-way analysis of variance, followed by a Bonferroni post-hoc test. $\mathrm{P}<0.05$ was considered to indicate a statistically significant difference.

\section{Results}

Expression of miRNA-766 in patients with colon cancer. Firstly, the present study analyzed changes in the expression of miRNAs in patients with colon cancer. As shown in Fig. 1A and $\mathrm{B}$, the expression of miRNA-766 in patients with colon cancer was elevated, compared with that in the control group. The overall survival (OS) and disease-free survival (DFS) rates of patients with colon cancer with a high expression of miRNA-766 were prolonged, compared with those with a low expression of miRNA-766 (Fig. 1C and D). The baseline characteristics of the 102 patients with colon cancer and 57 normal volunteers are shown in Table I. 
A

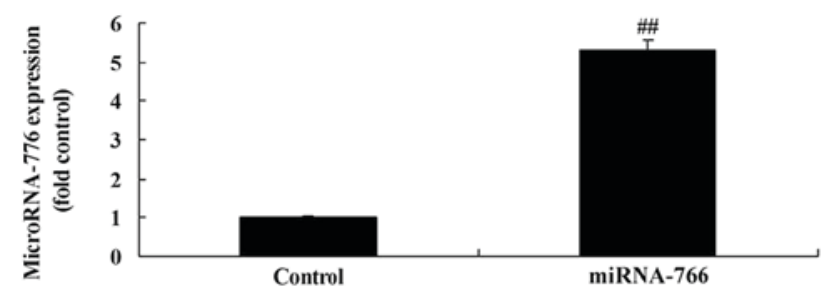

$\mathrm{C}$

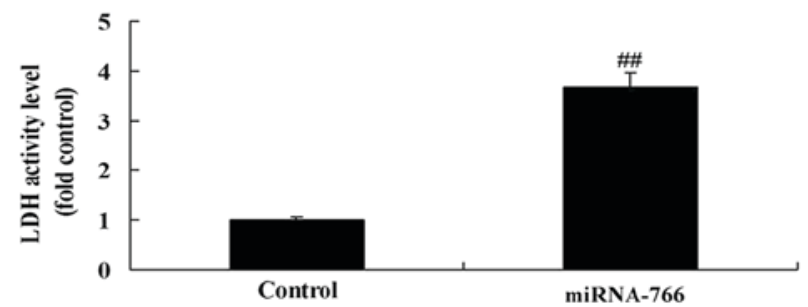

E

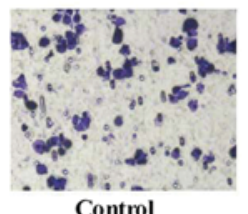

G

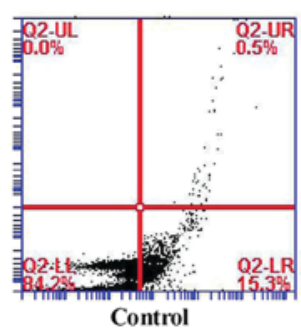

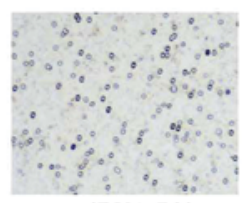

miRNA-766

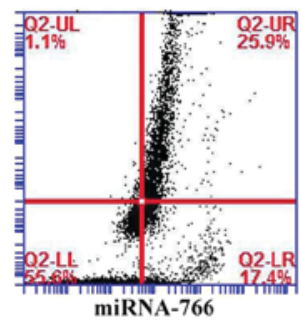

B

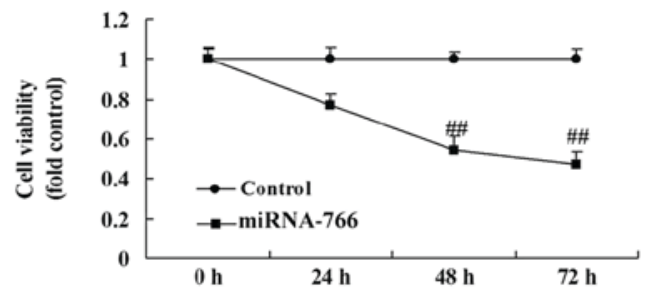

$\mathrm{D}$

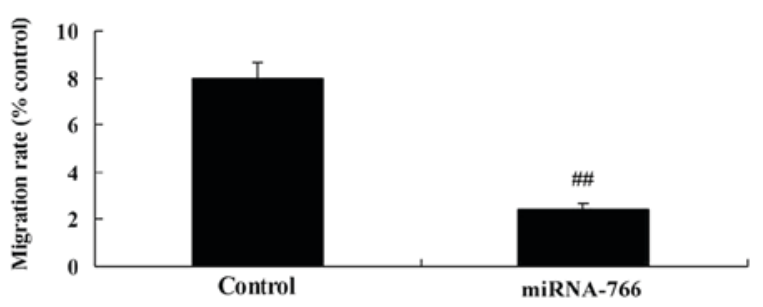

F

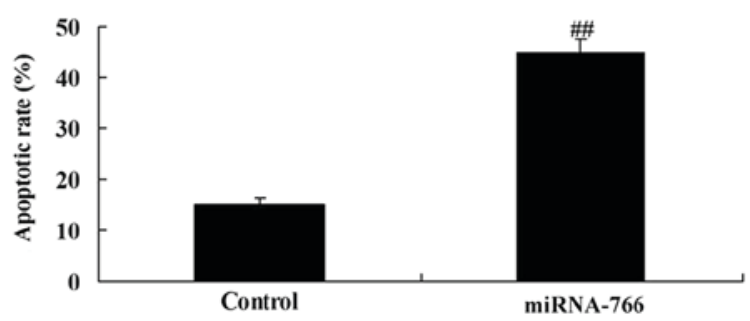

$\mathrm{H}$

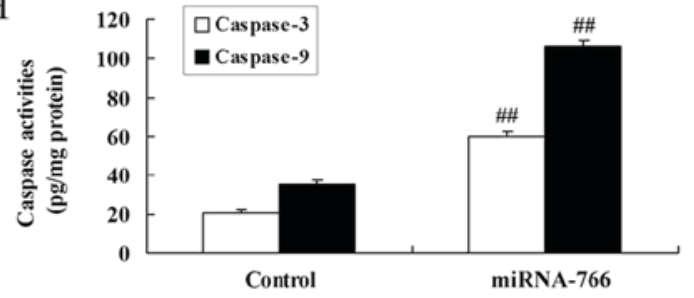

Figure 2. Overexpression of miRNA-766 regulates cell growth of colon cancer cells. (A) Expression of miRNA-766. (B) Cell growth. (C) LDH activity. (D) Cell migration rates and (E) images. Magnification, x100. (F) Apoptotic rates quantified from (G) flow cytometry. (H) Caspase-3/9 activity levels. ${ }^{\#} \mathrm{P}<0.01$, vs. Control. Control, negative control group; miRNA-766, overexpression of miRNA-766 group; miRNA, microRNA; LDH, lactate dehydrogenase.

miRNA-766 regulates cell growth of colon cancer cells. To examine the function of miRNA-766 in the cell growth of colon cancer cells, the present study analyzed the effects of miRNA-766 or anti-miRNA-766 on the growth of colon cancer cells. As shown in Fig. 2A, the expression of miRNA-766 was increased using miRNA-766 mimics in Caco2 cells, compared with that in the negative control group. The overexpression of miRNA-766 reduced cell growth and migration, and promoted lactate dehydrogenase (LDH) activity, apoptotic rate and caspase-3/9 activity levels in the Caco2 cells, compared with cells in the negative control group (Fig. 2B-H). Subsequently, it was confirmed that the expression of miRNA-766 was inhibited in Caco2 cells by using anti-miRNA-766 mimics, compared with expression in the negative control group (Fig. 3A). The downregulation of miRNA-766 promoted cell growth and migration, and reduced the LDH activity, apoptotic rate and caspase-3/9 activity levels in Caco2 cells, compared with cells in the negative control group (Fig. 3B-H).

miRNA-766 regulates the MDM4/p53 pathway in colon cancer cells. Subsequently, the present study examined the mechanism underlying the effect of miRNA-766 on colon cancer cell growth. As shown in Fig. 4A and B, the putative miR-766-binding sequence in the 3'UTR of MDM4 mRNA and luciferase activity was attenuated following the overexpression of miRNA-766, compared with the negative control group. However, the overexpression of miRNA-766 suppressed the protein expression of MDM4, and induced that of p53 and Bax in the Caco 2 cells, compared with the negative control group (Fig. 4C-F). The downregulation of miRNA-766 induced the protein expression of MDM4, and suppressed that of p53 and Bax in Caco 2 cells, compared with the negative control group (Fig. 4G-J).

Promotion of MDM4 attenuates the anticancer effect of miRNA-766 in colon cancer cells. To further assess the relevance of the miR-766/MDM4 interaction in p53 signaling, an MDM4 plasmid was utilized to induce the expression of MDM4 in Caco2 cells overexpressing miR-766. As shown in Fig. 5A-D, the MDM4 plasmid induced the protein expression of MDM4, and suppressed that of p53 and Bax in Caco2 cells overexpressing miR-766, compared with the cells overexpressing miR-766 without the plasmid. The overexpression of MDM4 promoted cell growth and migration, and reduced LDH activity, apoptotic rate and caspase-3/9 activity levels in 
A
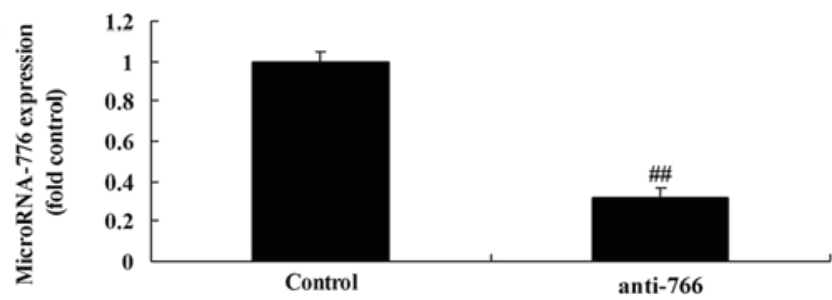

C

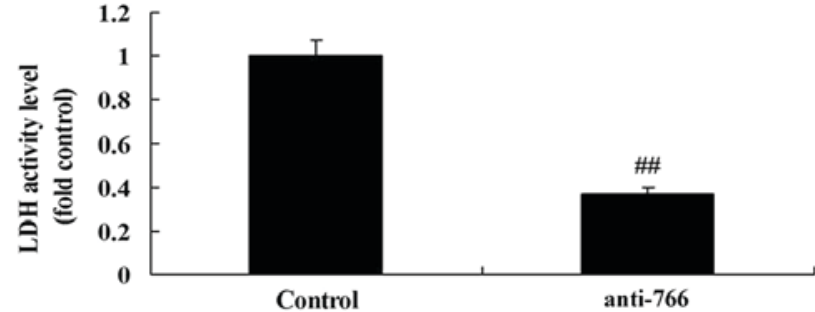

E

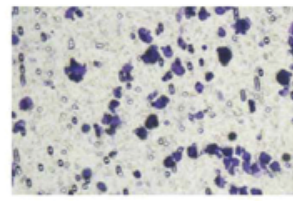

Control

G

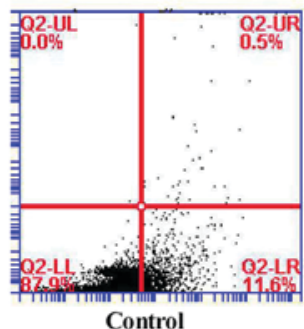

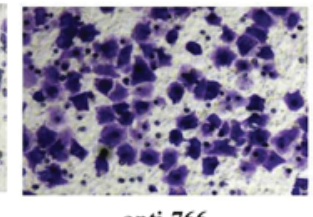

anti-766

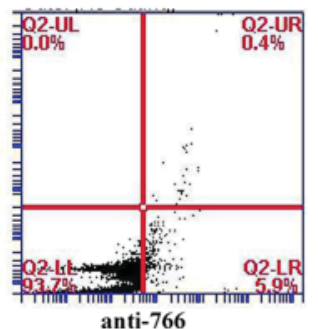

B

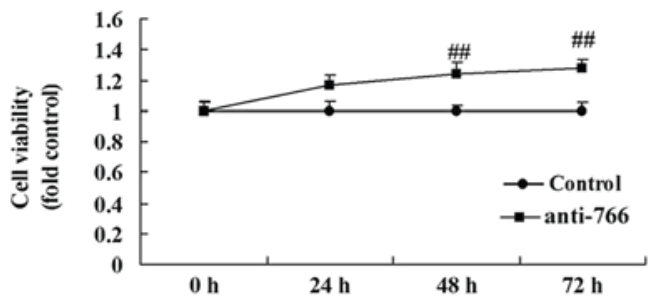

D

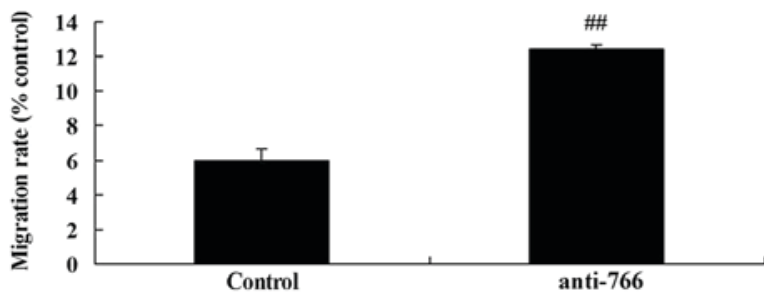

F

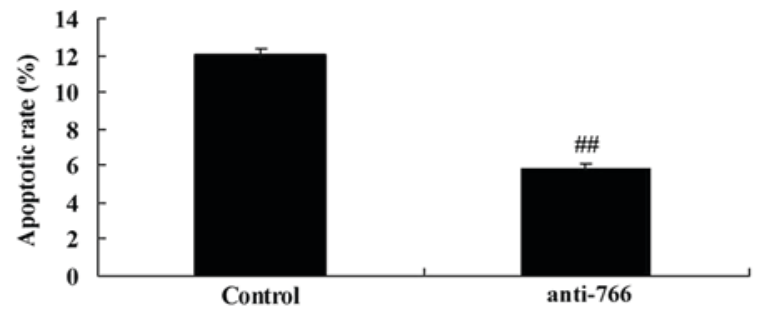

H

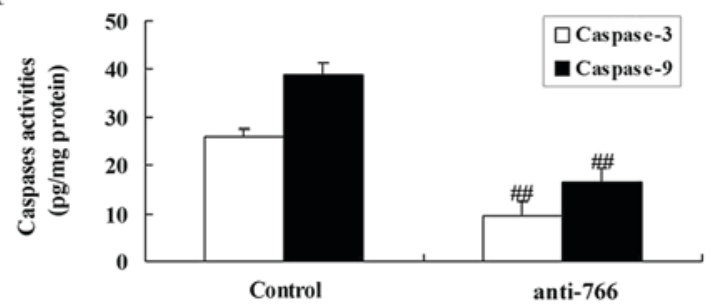

Figure 3. Downregulation of miRNA-766 regulates the growth of colon cancer cells. (A) Expression of miRNA-766. (B) Cell growth. (C) LDH activity. (D) Cell migration rate and (E) images. Magnification, x100. (F) Apoptotic rate quantified from (G) flow cytometry. (H) Caspase-3/9 activity levels. ${ }^{\# \# / P}<0.01$, vs. Control. Control, negative control group; anti-766, downregulation of miRNA-766 group; anti-766, downregulation of miRNA-766 group; miRNA, microRNA; LDH, lactate dehydrogenase.

the Caco2 cells overexpressing miR-766, compared with the negative control group (Fig. 5E-K).

\section{Discussion}

Colon cancer has a complicated pathogenic process (14). It is controlled by multiple genes, has different stages, and is formed over a long period (14). Early diagnosis, together with tumor recurrence monitoring and effective development of novel treatments, is important for patients with colon cancer (13). It has been found in previous years that several miRNAs exist in colon cancer tissues and patient blood, and are important in the pathogenesis of colon cancer (15). In the in vitro experiments performed in the present study, the expression of miRNA-766 in patients with colon cancer was increased, compared with that in the control group. The OS and DFS rates of patients with colon cancer and a high expression of miRNA-766 were higher than those of patients with colon cancer and a low expression of miRNA-766. Oh et al showed that miRNA-766 affected the distant metastatic process to a greater extent than cancer cell proliferation and primary tumor growth of human triple-negative breast cancer cells (16). Jia et al showed that miR-766-5p suppressed the tumor growth of colorectal cancer (17). However, the present study used only one cell line, Caco2 cells, which is insufficient for this investigation.

miR-191, which locates in human 3p21.3, has been found to be overexpressed in numerous types of human tumor (18). For example, a high expression of miR-191 has been found in liver, stomach, large intestine, prostate, and breast cancer (19). It was found in liver cancer that miRNA-191 promotes epithelial-mesenchymal transition and exerts its tumor-promoting effect through suppressing the expression of TIM3; it may serve as a novel target in the treatment of liver cancer (15). It was confirmed in a study on gastric cancer that miRNA-191 promotes gastric cancer cell growth and inhibits cell apoptosis through its target gene NDST1 (15). In the present study, the overexpression of miRNA-766 reduced cell growth and cell migration, and promoted LDH activity, apoptotic rate and caspase-3/9 activity levels in Caco2 cells.

Colon cancer is one of the most common malignancies clinically. As indicated in numerous studies, tumorigenesis and development is linked with disruption to the dynamic balance between cell proliferation and apoptosis (19). Bcl-2 family proteins are important regulatory factors of cell 
A
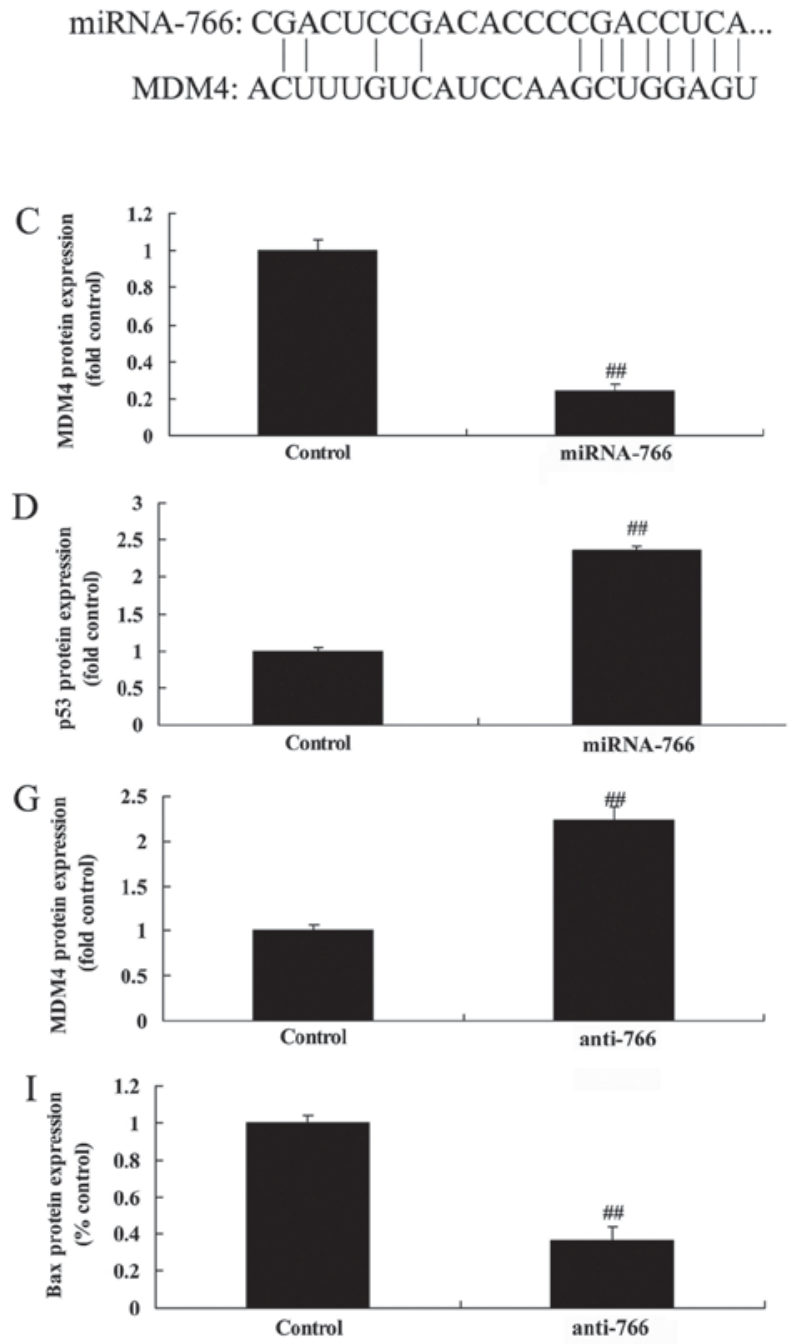

$\mathrm{B}$
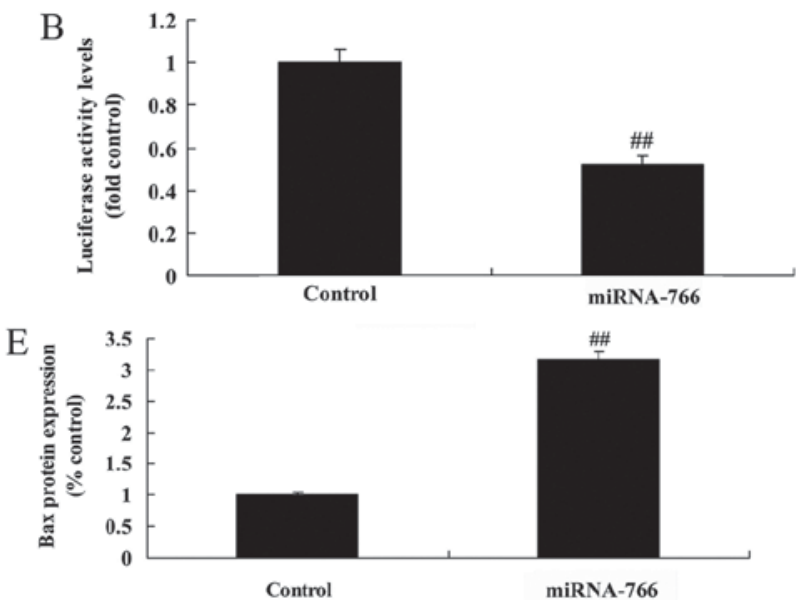

$\mathrm{F}$
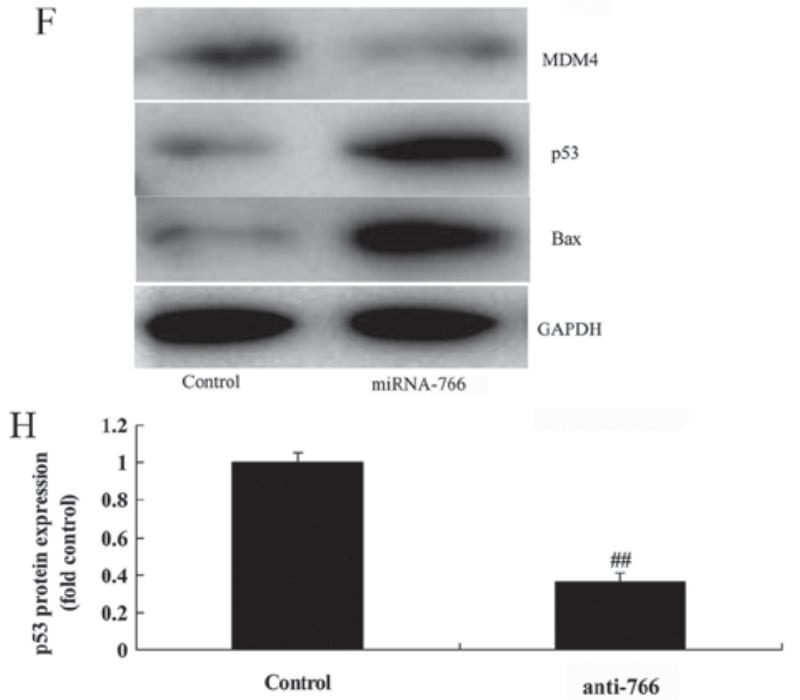

$\mathrm{J}$

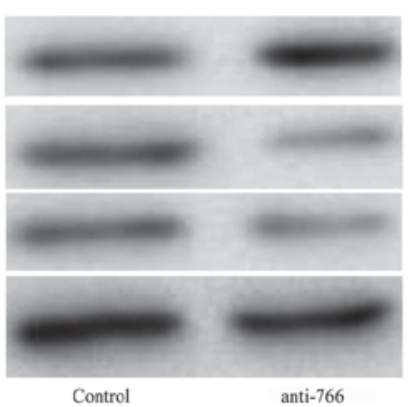

Figure 4. miRNA-766 regulates the MDM4/p53 pathway of colon cancer cells. (A) Putative miRNA-766-binding sequence in the 3'untranslated region of MDM4 mRNA. (B) Luciferase activity. Statistical analysis of protein expression levels of (C) MDM4, (D) Bax and (E) p53 from (F) bands of MDM4, Bax and p53 proteins in cells with overexpression of miRNA-766. Statistical analysis of protein expression levels of (G) MDM4, (H) Bax and (I) p53 from (J) bands of Bax and p53 proteins in cells with downregulation of miRNA-766. ${ }^{\# \#} \mathrm{P}<0.01$, vs. Control. Control, negative control group; miRNA-766, overexpression of miRNA-766 group; anti-766, downregulation of miRNA-766 group; Bax, B-cell lymphoma 2-associated X protein.

apoptosis, which can inhibit cell apoptosis, for example Bcl-2 and Bcl-extra large, or promote apoptosis, for example, Bax and BCL2-antagonist/killer. Changes in expression not only affect DNA injury or normal apoptosis of cells with abnormal cell cycle, but also affect the apoptosis of tumor cells. The majority of antitumor drugs exert cytotoxic effects through inducing tumor cell apoptosis (20). In the present study, the overexpression of miRNA-766 suppressed the protein expression of MDM4, and induced the protein expression of p53 and Bax in Caco2 cells.

Tumor suppressor p53 is important in regulating cell cycle, apoptosis, DNA injury and aging (21). It is the gene that is most susceptible to mutation in human tumors. It is reported that $\sim 50 \%$ of human tumors are associated with abnormalities in the p53 gene, leading to p53 gene inactivation and abnormal p53 protein function. Inhibition or inactivation of the $\mathrm{p} 53$ gene frequently promotes tumorigenesis (22). Numerous factors are involved in the activation of p53, including the MDM4 gene and MDM2 gene (23). MDM4 and MDM2 are considered to be p53 inhibitors, which can regulate p53 activity (23). FL-MDM4 inhibits p53-mediated transcriptional activity, and gives rise to cell cycle arrest and apoptosis (24). MDM2 mainly mediates p53 degradation through E3 ubiquitin ligase. The overexpression or proliferation of FL-MDM4 has been observed in human solid tumors and tumor cell lines. The overexpression 
A

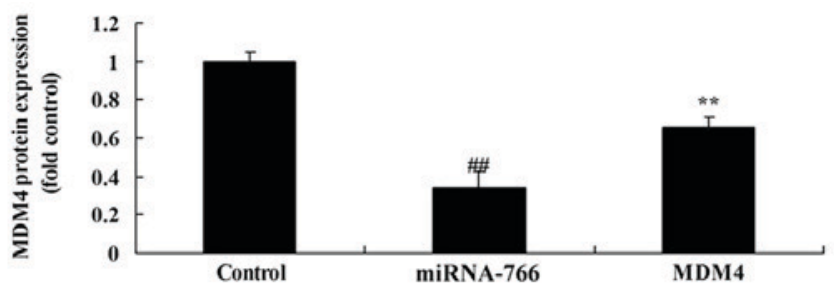

$\mathrm{C}$

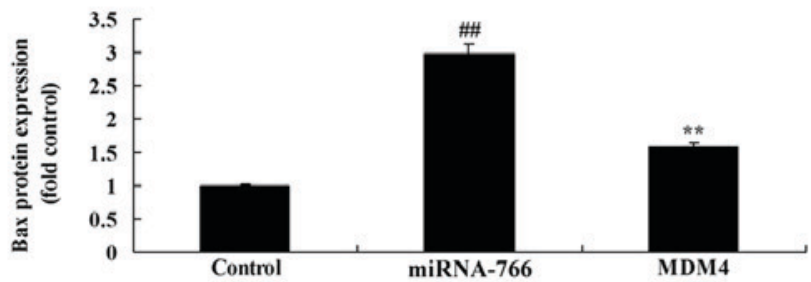

E

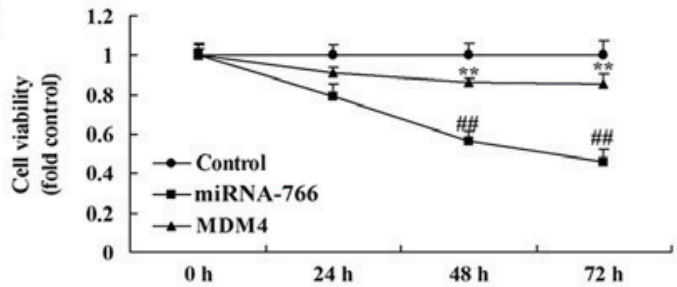

G
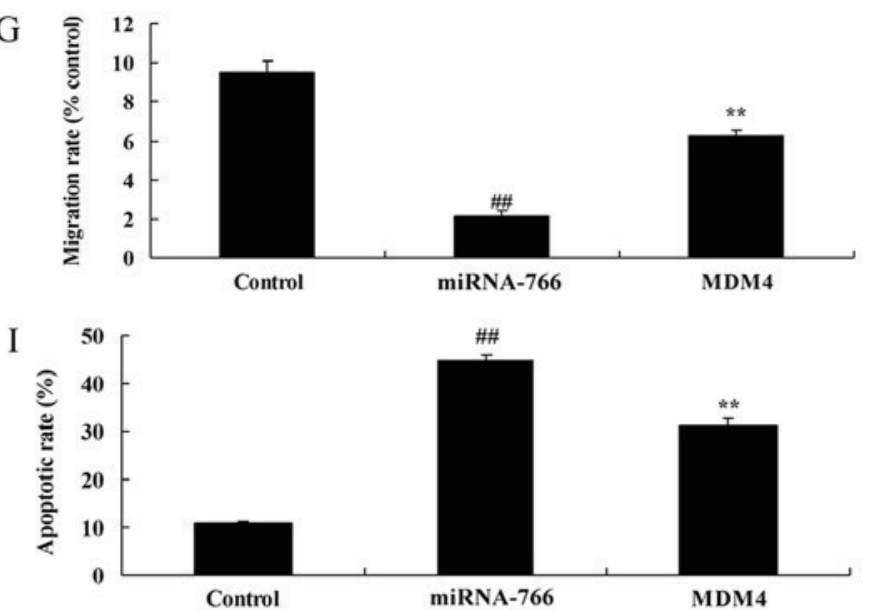

$\mathrm{B}$

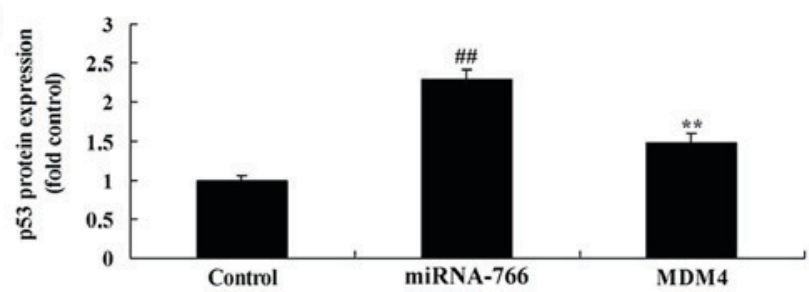

$\mathrm{D}$
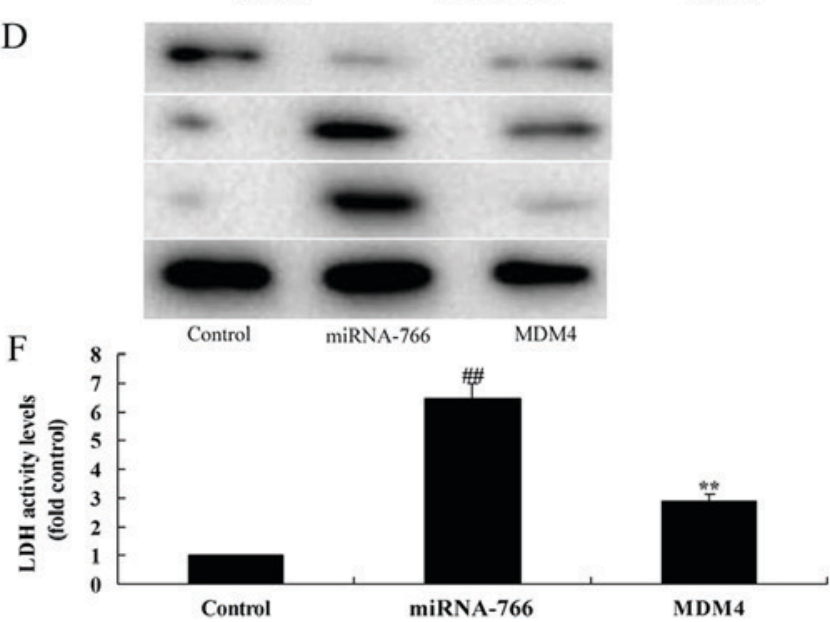

$\mathrm{H}$
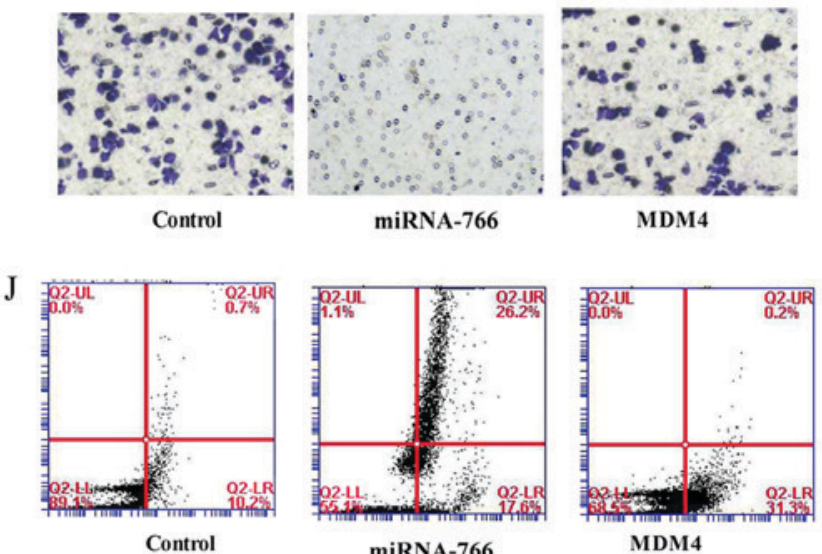

MDM4

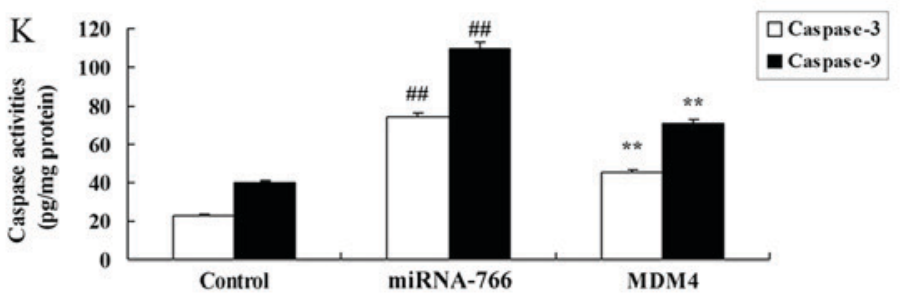

Figure 5. Promotion of MDM4 reduces the anticancer effect of miRNA-766 in colon cancer cells. Statistical analysis of protein expression levels of (A) MDM4, (B) Bax and (C) p53 from (D) MDM4, Bax and p53 protein bands. (E) Cell growth. (F) LDH activity. (G) Cell migration rate and (H) images. Magnification, $\mathrm{x} 100$. (I) Apoptotic rate quantified from (J) flow cytometry. (K) Caspase-3/9 activity levels. ${ }^{\# \#} \mathrm{P}<0.01$ vs. Control; ${ }^{* *} \mathrm{P}<0.01$ vs. miRNA-766. Control, negative control group; miRNA-766, overexpression of miRNA-766 group; MDM4, MDM4 and overexpression of miRNA-766 group. miR, microRNA; Bax, B-cell lymphoma 2-associated X protein.

of FL-MDM4 mRNA can be detected in colon cancer cells through RT-qPCR analysis, as reported previously (24). In the present study, the promotion of MDM4 reduced the anticancer effect of miRNA-766 in colon cancer cells. Wang et al also demonstrated that miRNA-766 induced p53 accumulation and G2/M arrest by directly targeting MDM4 in breast cancer (25).

In conclusion, the data obtained in the present study demonstrated that miRNA-766 reduced cell growth and cell migration, and promoted LDH activity, apoptotic rate and caspase-3/9 activity levels through MDM4/p53 in Caco2 cells (Fig. 6). These findings provide a direct link between miR-766/MDM4 and human colon cancer survival rate and cell grow th, which provides insight into the p53/Bax pathway. Additionally, these results support the hypothesis that genetic variants can interrupt miR-766-mediated gene regulation, and this type of regulatory gene may be important modifiers of human colon cancer risk. 


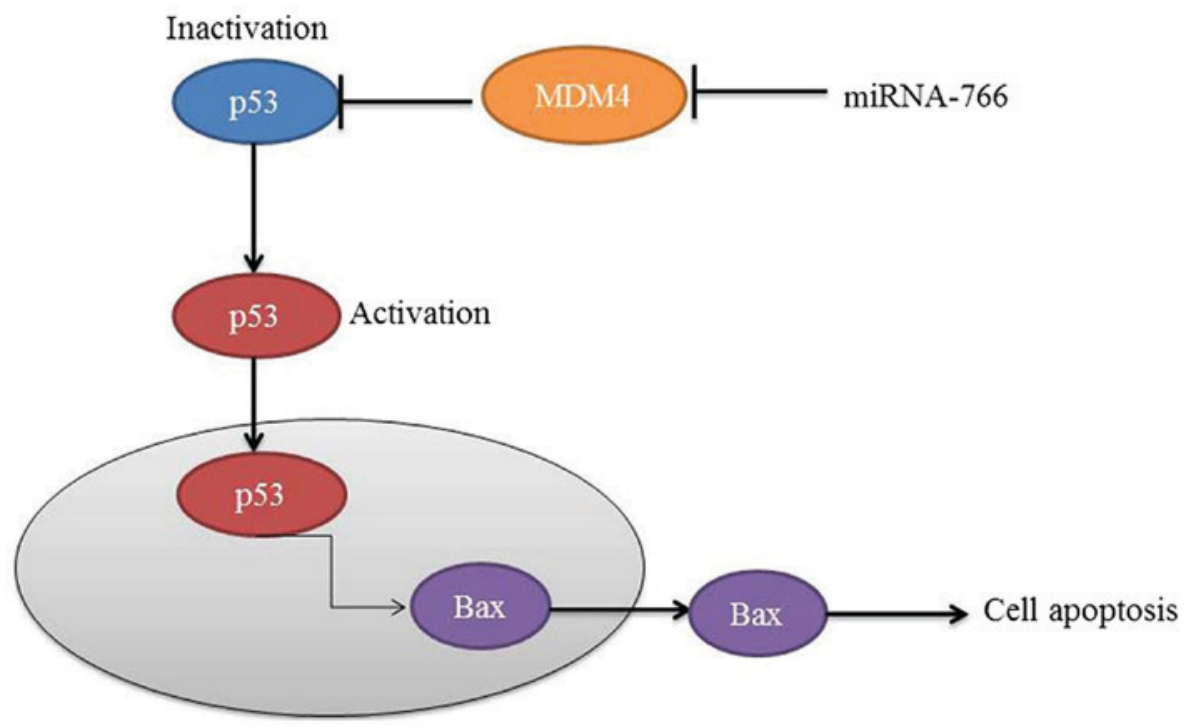

Figure 6. miRNA-766 induces cell apoptosis in human colon cancer through MDM4/p53. miRNA, microRNA; Bax, B-cell lymphoma 2-associated X protein.

\section{Acknowledgements}

Not applicable.

\section{Funding}

No funding was received.

\section{Availability of data and materials}

The analyzed data sets generated during the study are available from the corresponding author on reasonable request.

\section{Authors' contributions}

WC designed the experiments; GC, ZL, KL, GL and YL performed the experiments; WC and GC analysed the data; and WC wrote the manuscript.

\section{Ethics approval and consent to participate}

The present study was approved by the Ethical Agent Will of the Second Affiliated Hospital, Shantou University Medical College.

\section{Patient consent for publication}

Not applicable.

\section{Competing interests}

The authors declare that they have no competing interests

\section{References}

1. Liu X, Zhao W, Wang W, Lin S and Yang L: Puerarin suppresses LPS-induced breast cancer cell migration, invasion and adhesion by blockage NF- $\kappa$ B and Erk pathway. Biomed Pharmacother 92: 429-436, 2017.
2. Gan M and Yin X: Puerarin induced in mantle cell lymphoma apoptosis and its possible mechanisms involving multi-signaling pathway. Cell Biochem Biophys 71: 367-373, 2015.

3. Adlakha YK and Saini N: miR-128 exerts pro-apoptotic effect in a 553 transcription-dependent and -independent manner via PUMA-Bak axis. Cell Death Dis 4: e542, 2013.

4. Ye Y, Zhuang J, Wang G, He S, Ni J and Xia W: MicroRNA-139 targets fibronectin 1 to inhibit papillary thyroid carcinoma progression. Oncol Lett 14: 7799-7806, 2017.

5. Wang H, Li XT, Wu C, Wu ZW, Li YY, Yang TQ, Chen GL Xie XS, Huang YL, Du ZW and Zhou YX: miR-132 can inhibit glioma cells invasion and migration by target MMP16 in vitro. Onco Targets Ther 8: 3211-3218, 2015.

6. Li JZ, Wang ZL, Xu WH, Li Q, Gao L and Wang ZM: MicroRNA-495 regulates migration and invasion in prostate cancer cells via targeting Akt and mTOR signaling. Cancer Invest 34: 181-188, 2016.

7. Yao C, Shi X, Zhang Z, Zhou S, Qian T, Wang Y, Ding F, Gu X and $\mathrm{Yu}$ B: Hypoxia-induced upregulation of miR-132 promotes Schwann cell migration after sciatic nerve injury by targeting PRKAG3. Mol Neurobiol 53: 5129-5139, 2016.

8. Leinders M, Üceyler N, Pritchard RA, Sommer C and Sorkin LS: Increased miR-132-3p expression is associated with chronic neuropathic pain. Exp Neurol 283: 276-286, 2016.

9. Xu Q, Zhang M, Tu J, Pang L, Cai W and Liu X: MicroRNA-122 affects cell aggressiveness and apoptosis by targeting PKM2 in human hepatocellular carcinoma. Oncol Rep 34: 2054-2064, 2015.

10. Prasad NB, Kowalski J, Tsai HL, Talbot K, Somervell H, Kouniavsky G, Wang Y, Dackiw AP, Westra WH, Clark DP, et al: Three-gene molecular diagnostic model for thyroid cancer. Thyroid 22: 275-284, 2012.

11. Imamura T, Komatsu S, Ichikawa D, Miyamae M, Okajima W, Ohashi T, Kiuchi J, Nishibeppu K, Konishi H, Shiozaki A, et al: Depleted tumor suppressor miR-107 in plasma relates to tumor progression and is a novel therapeutic target in pancreatic cancer. Sci Rep 7: 5708, 2017.

12. Xu T, Pang Q, Wang Y and Yan X: Betulinic acid induces apoptosis by regulating PI3K/Akt signaling and mitochondrial pathways in human cervical cancer cells. Int J Mol Med 40: 1669-1678, 2017.

13. Livak KJ and Schmittgen TD: Analysis of relative gene expression data using real-time quantitative PCR and the 2(-Delta Delta C(T)) method. Methods 25: 402-408, 2001.

14. Lages E, Guttin A, El Atifi M, Ramus C, Ipas H, Dupré I, Rolland D, Salon C, Godfraind C, deFraipont F, et al: MicroRNA and target protein patterns reveal physiopathological features of glioma subtypes. PLoS One 6: e20600, 2011.

15. Eun JW, Kim HS, Shen Q, Yang HD, Kim SY, Yoon JH, Park WS, Lee JY and Nam SW: MicroRNA-495-3p functions as a tumour suppressor by regulating multiple epigenetic modifiers in gastric carcinogenesis. J Pathol 244: 107-119, 2018. 
16. Oh $\mathrm{K}$ and Lee DS: In vivo validation of metastasis-regulating microRNA-766 in human triple-negative breast cancer cells. Lab Anim Res 33: 256-263, 2017.

17. Jia B, Xia L and Cao F: The role of miR-766-5p in cell migration and invasion in colorectal cancer. Exp Ther Med 15: 2569-2574, 2018.

18. Zaharieva ET, Kamenov ZA and Savov AS: TLR4 polymorphisms seem not to be associated with prediabetes and type 2 diabetes but predispose to diabetic retinopathy; TLR4 polymorphisms in glucose continuum. Endocr Regul 51: 137-144, 2017.

19. Bahadori M, Baharara J and Amini E: Anticancer properties of Chrysin on colon cancer cells, in vitro and in vivo with modulation of caspase-3, -9, Bax and Sall4. Iran J Biotechnol 14 177-184, 2016

20. LeBlanc H, Lawrence D, Varfolomeev E, Totpal K, Morlan J, Schow P, Fong S, Schwall R, Sinicropi D and Ashkenazi A: Tumor-cell resistance to death receptor-induced apoptosis through mutational inactivation of the proapoptotic Bcl-2 homolog Bax. Nat Med 8: 274-281, 2002.

21. Wang J, Chu ES, Chen HY, Man K, Go MY, Huang XR, Lan HY, Sung JJ and Yu J: microRNA-29b prevents liver fibrosis by attenuating hepatic stellate cell activation and inducing apoptosis through targeting PI3K/AKT pathway. Oncotarget 6: 7325-7338, 2015 .
22. Yang SD, Ma L, Yang DL and Ding WY: Combined effect of $17 \beta$-estradiol and resveratrol against apoptosis induced by interleukin-1 $\beta$ in rat nucleus pulposus cells via PI3K/Akt/caspase-3 pathway. PeerJ 4: e1640, 2016.

23. Li Z, Shen J, Wu WK, Yu X, Liang J, Qiu G and Liu J: Leptin induces cyclin D1 expression and proliferation of human nucleus pulposus cells via JAK/STAT, PI3K/Akt and MEK/ERK pathways. PLoS One 7: e53176, 2012

24. Chen HX, Xu XX, Tan BZ, Zhang Z and Zhou XD: MicroRNA-29b inhibits angiogenesis by targeting VEGFA through the MAPK/ERK and PI3K/Akt signaling pathways in endometrial carcinoma. Cell Physiol Biochem 41: 933-946, 2017.

25. Wang Q, Selth LA and Callen DF: MiR-766 induces p53 accumulation and G2/M arrest by directly targeting MDM4. Oncotarget 8: 29914-29924, 2017.

(i) (9) This work is licensed under a Creative Commons Attribution-NonCommercial-NoDerivatives 4.0 International (CC BY-NC-ND 4.0) License. 